\title{
Emerger. \\ La imagen traumática en Gus Van Sant
}

\author{
Paranoid Park | Gus Van Sant | 2007 \\ Frédérique Hammerli*
}

Recibido: 7 de enero 2018; aceptado: 13 de abril 2018

\begin{abstract}
Resumen
El cine de Gus Van Sant rebosa de personajes que se han enfrentado a un evento traumático. Es difícil ignorar la recurrencia del trauma en la obra del cineasta, desde las primeras películas hasta las últimas. En este trabajo examinaremos algunas modalidades del tratamiento narrativo de este tópico a través del caso ejemplar de Paranoid Park, con el objetivo de evidenciar el hecho de que Gus Van Sant no se interesa tanto, desde el punto de vista del personaje, en el trauma en sí o en sus consecuencias dolorosas, sino más bien en una posible superación del acontecimiento por medio de su elaboración. Esto permitirá extraer lo que este tópico revela del trabajo del cineasta, de su enfoque de la imagen y del poder que esta ejerce sobre el espectador, es decir, de su concepción misma de la función del cine.
\end{abstract}

Palabras Clave: Trauma | superación del acontecimiento | imagen | poder | función del cine

\begin{abstract}
Gus Van Sant's cinema is full of characters who have been confronted with a traumatic event. It is difficult to ignore the recurrence of trauma in the filmmaker's work, from the very first films to the last. In this work, we examine some modalities of narrative treatment through the exemplary case of Paranoid park to highlight the fact that Gus van Sant is less interested, from the point of view of the character, the trauma itself or his painful consequences, only to a possible overtaking of the event through its elaboration. This will bring out what this motif reveals about the filmmaker's work, his approach to the image and the power it exerts on the viewer, and thus its very conception of the function of cinema.
\end{abstract}

Key Words: Trauma | overcoming the event | image | power | function of cinema

El cine de Gus Van Sant rebosa de personajes que se han enfrentado, en su pasado, a un evento traumático: actos de violencia física o mental, abusos sexuales, muertes de duelo imposible. Es el caso, por dar algunos ejemplos, de Mike en My own private Idaho (1991), de los adolescentes de To die for (1995), de Will en Will Hunting (1997), de Forrester en Meeting Forrester (2000), de Alex en Paranoid Park (2007) y de Enoch en Restless (2011). Es difícil, entonces, ignorar la recurrencia del trauma en la obra del cineasta, desde las primeras películas hasta las últimas, recurrencia que la crítica ha señalado en numerosas ocasiones.

En este trabajo examinaremos, primero, algunas modalidades del tratamiento narrativo de este tópico a través del caso ejemplar de Paranoid Park, con el objetivo de evidenciar el hecho de que Gus Van Sant no se interesa tanto, desde el punto de vista del personaje, en el trauma en sí o en sus consecuencias dolorosas, sino más bien en una posible superación del acontecimiento por medio de su elaboración. Esto permitirá extraer lo que este tópico revela del trabajo del cineasta, de su enfoque de la imagen y del poder que esta ejerce sobre el espectador, es decir, de su concepción misma de la función del cine.

\section{Un caso ejemplar: Paranoid Park}

Paranoid Park constituye un caso ejemplar del papel del traumatismo en la obra de Gus Van Sant ya que presenta un evento traumático en el corazón mismo de la película: un sábado por la noche, Alex, el personaje principal, un adolescente, se dirige a Paranoid Park, donde encuentra a un skater más grande que él, Scratch, que lo lleva a colgarse de los trenes en una estación de carga. Cuando se defiende del ataque de un guardia de 
seguridad que los persigue, Alex provoca involuntariamente la caída mortal de este último. Un tren que pasa parte su cuerpo a la mitad. El adolescente, confrontado a esta muerte violenta, se da a la fuga y no habla del hecho con nadie. El mutismo de Alex se debe a que sufrió una efracción psíquica que le bloquea el acceso a toda forma de entendimiento de lo que ha vivido. Al verse confrontado a la muerte del guardia, lo que ha encontrado es la muerte en toda su potencia. Toda representación del evento y todo discurso con respecto a él se le vuelven imposibles. Hay tres elementos fílmicos que lo prueban. En primer lugar, la construcción narrativa da cuenta tanto de la ocultación de la escena traumática como de su resurgimiento brutal. En efecto, en la primera parte de la película, la rememoración de Alex no permite tener una visión clara del accidente. Para eso, habrá que esperar a la mitad de la película. El retorno de la escena traumática es, primero, un retorno repentino que el personaje sufre y que se desencadena cuando Alex fija la mirada en las fotos de la escena del hecho que le muestra el inspector Lu, encargado de la investigación de la muerte del guardia. Agreguemos que la experiencia traumática de Alex se asocia al susto, que se puede definir como una ausencia de miedo o de angustia, acompañado de una especie de "blackout", una "suspensión en la imagen", una forma de parálisis total. Desde el inicio de la película, cuando todavía ignoramos lo que le ha pasado a Alex, él parece anestesiado, y es lo que transmite la puesta en escena mediante la utilización de poca profundidad de campo o de sonidos ahogados, por ejemplo. Alex está en una especie de burbuja que también se vuelve nuestra.

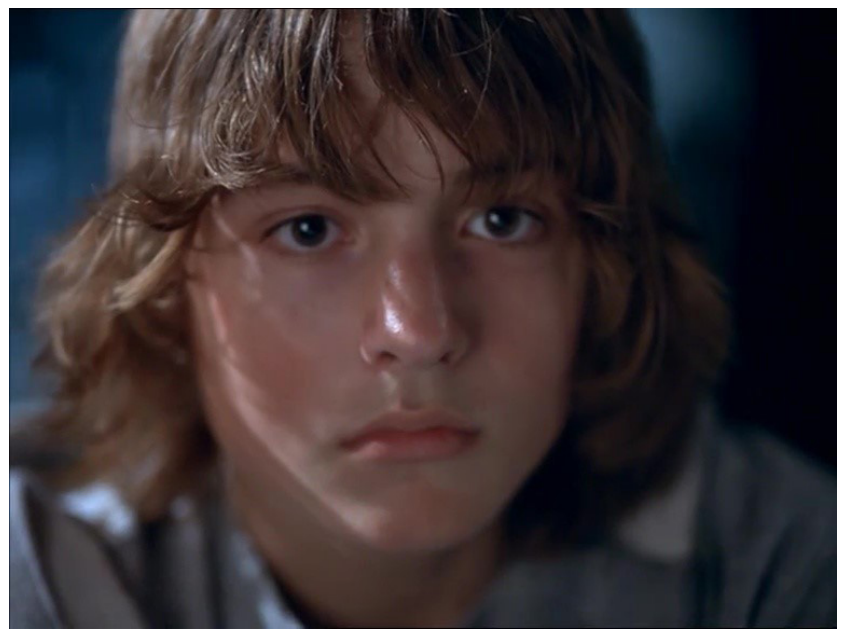

Por último, si hay susto, sideración, es porque la experiencia traumática está asociada a la sorpresa, que es una condición necesaria para la incapacidad del sujeto de afrontar el hecho porque no ha sido preparado para ello. Alex comenta retrospectivamente la propuesta de su amigo Jared de ir a patinar a Paranoid Park de la siguiente manera: "I was not prepared for Paranoid Park" [No estaba listo para Paranoid Park]. Alex substituye "Paranoid Park” al evento, que surgió brutalmente, sin preparación. Como la escena traumática se volvió inaccesible, lo que expresa el trauma, al principio de la película, son esas dos palabras: no solo el nombre mismo del parque de skate puede sugerir el susto, sino que retorna de manera compulsiva. Evidentemente, ese es el título de la película misma, pero también del diario que empieza Alex desde el primer plano de la película, escena que reaparece más tarde. La mente de Alex y la película tropiezan con una palabra que no puede constituirse y con una imagen que no puede elaborarse.
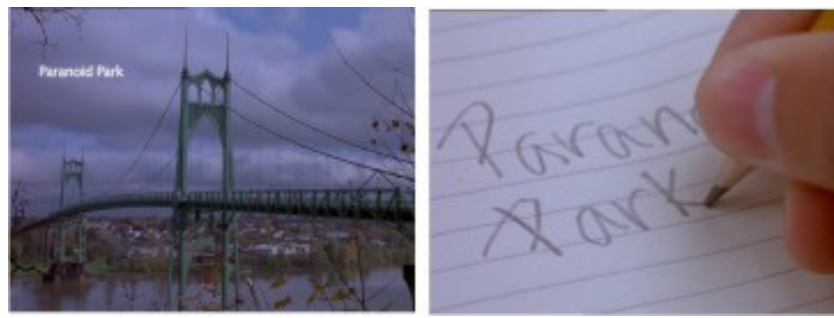

Un doble título: los primeros planos de Paranoid Park o cuando la imagen tartamudea.

Sin embargo, la película no es el relato de una catástrofe y de sus consecuencias, sino más bien el de su aprehensión progresiva por parte del personaje. En efecto, el tartamudeo en la expresión "Paranoid Park" señala también un proceso de transformación en obra: del hecho en sí mismo a su puesta en relato y en película. Más que a un principio cronológico y lineal, la película se ajusta al proceso de escritura del diario que Alex comienza a redactar en la presentación y que tira al fuego cuando esta termina, cuando su relato se ha terminado. El montaje, la construcción de la película, da cuenta, en el plano narrativo, de la manera en que Alex enfrenta el trauma que produjo en él la muerte del guardia. La observación de la estructura de la película es muy instructiva en este sentido. La película se desarrolla en tres partes, cada una de las cuales alterna las fases de escritura del diario y la rememoración que deriva de ellas. Un primer relato elíptico y acronológico contiene en su centro una evocación fugitiva de los acontecimientos que precedieron y sucedieron al accidente, sin representación directa de este último. La segunda parte, que empieza con la reaparición de la expresión "Paranoid Park" que Alex escribe en su diario, tiene en su seno un relato elaborado, frontal y cronológico de la noche en la 
que tuvo lugar el accidente y del accidente en sí mismo. La tercera y última parte constituye un retorno al silencio, que pasa, especialmente, por el hecho de que Alex quema el diario en el que registró, es decir, elaboró, el evento. Una construcción tal pone de manifiesto el hecho de que la escena que estructura Paranoid Park es la del accidente que condujo a la muerte del guardia de seguridad. Esta escena está en el corazón de las dos primeras partes, su aparición literal se sitúa en el medio de la película y es su desaparición, como disolución de la escena traumática, lo que motiva la tercera parte. A través de los recuerdos que registra, algunos de los cuales tienen que ver con la escuela, sus padres, su novia Jennifer, Alex realiza, en cierto modo, dos veces el mismo recorrido: la primera vez, de manera muy alusiva; la segunda, de manera mucho más explícita, como si girara alrededor del accidente, antes de poder pasar a otra cosa, volver a ponerse en movimiento. El personaje pasa de la ocultación traumática a la elaboración de una representación del hecho que le permite, en un último momento, abstraerse de él, es decir, escapar de la sideración de la mirada y de la desaparición. Para el sujeto, se trata entonces de emerger, lo que sucede por medio de una construcción en círculo, un ascenso en espiral hacia la superficie.

El recorrido que experimenta el espectador es completamente diferente: antes de que intervenga la escena del accidente, se enfrenta primero al discurso de Alex, que es confuso, elíptico, alusivo, no cronológico. Para el espectador, el discurso que se construye es, entonces, lo que permite la aparición de la imagen, mientras que para Alex es el resurgimiento compulsivo de la escena traumática, por medio de una fotografía de la escena del accidente, lo que desencadena la necesidad del discurso, de la puesta en palabras. Además, el recorrido del espectador sigue una lógica lineal, la de la llegada progresiva y esperada de la imagen, bien alejada de la construcción en espiral del relato de Alex. En efecto, Gus Van Sant nos prepara para la aparición de la imagen violenta del accidente organizando un recorrido perfectamente lineal desde este punto de vista. (Ver figura al pie).

La película organiza entonces dos recorridos, el del personaje y el del espectador, según dos lógicas diferentes. Todo sucede como si la película estuviera dotada de dos centros, dos focos de una misma elipse, alrededor de los cuales el relato se enrosca en espiral. En el centro del recorrido de Alex, se sitúa la fotografía del cadáver que desencadena la rememoración, que es además el centro "matemático" de la película, si tomamos su duración sin los créditos finales. En el centro del recorrido del espectador, interviene la visión de la escena del accidente, que es entonces prioritariamente percibida por el espectador. La puesta en escena del accidente mismo corresponde a esos dos focos perspectivos diferentes: Alex y el espectador. En la primera parte de esa escena, el sentido de los desplazamientos de Alex, de Scratch, al que sigue hasta la estación ferroviaria, y de los trenes conecta de un plano a otro: el tren al que se suben Alex y Scratch va de izquierda a derecha o del primer plano al segundo plano. Tras la

\section{Orden de la película, según cómo el espectador descubre las imágenes del accidente}

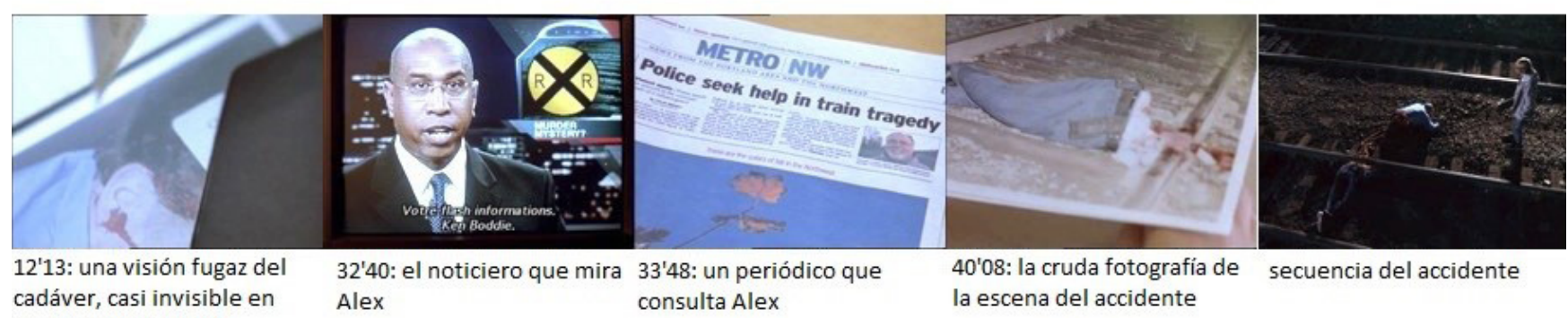
los documentos del inspector Lu

Cronología real para Alex, en el orden en el que vivió los acontecimientos: la imagen emerge antes de desaparecer

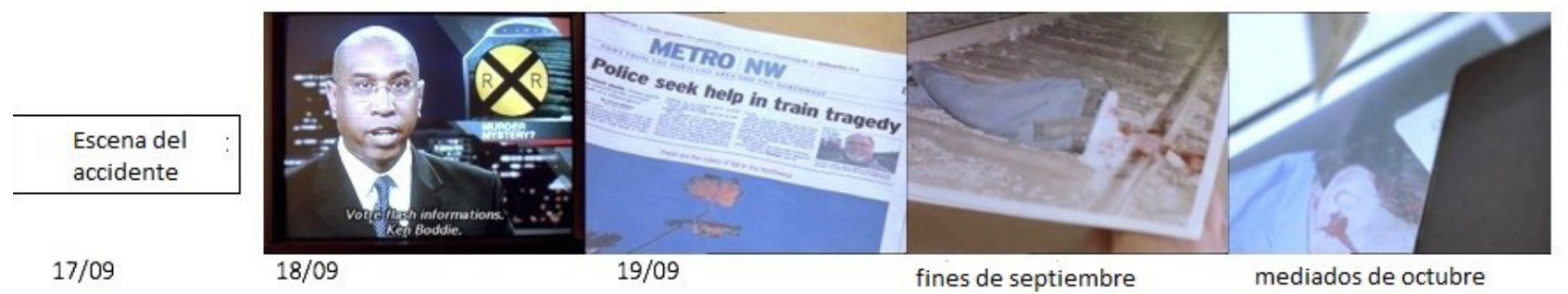


caída del guardia, los sentidos se vuelven incoherentes y alternan entre derecha/izquierda e izquierda/derecha, a tal punto que Alex parece surgir de una dirección imposible cuando cae cara a cara con el guardia herido. Esta desconexión de los espacios coincide con la dificultad de Alex de seguir una cronología en el conjunto de su relato. Podríamos decir que la imagen del cuerpo dividido del guardia provocó un quiebre del espacio y el tiempo. Pero eso conduce también a considerar que lo que nosotros vemos del accidente no es más que el fruto de una re-presentación: la escena no habría sido percibida realmente por Alex. Se opera una disyunción entre el punto de vista de Alex y el del espectador, disyunción que se confirma por los ángulos de cámara. Cuando Alex permanece frente al guardia, se nos ofrece a los espectadores un punto de vista lateral en picado del cuerpo del hombre, punto de vista que no puede ser el del personaje. Este punto de vista no es tampoco el de las fotografías tomadas por la policía científica, que se nos permitió divisar antes en la película. Todo sucede como si Gus Van Sant nos hiciera ver una escena imposible, una imagen de cine que no estaría dirigida ni destinada a nadie más que al espectador.

Además, el final de la secuencia señala que la imagen traumatizante a la que Alex se confronta es, ciertamente, la de un cuerpo rebanado en dos, pero sobre todo, de una mirada, siderante, la de un hombre frente a la muerte. En efecto, una serie de falsos campo-contracampo alterna el rostro en primer plano del guardia, el de Alex y luego el del inspector Lu. La iluminación antinatural de la mirada de $\mathrm{Lu}$ pone de manifiesto la importancia de los intercambios de mirada, y el rol central del rostro en la reactivación de la imagen traumática y su elaboración.
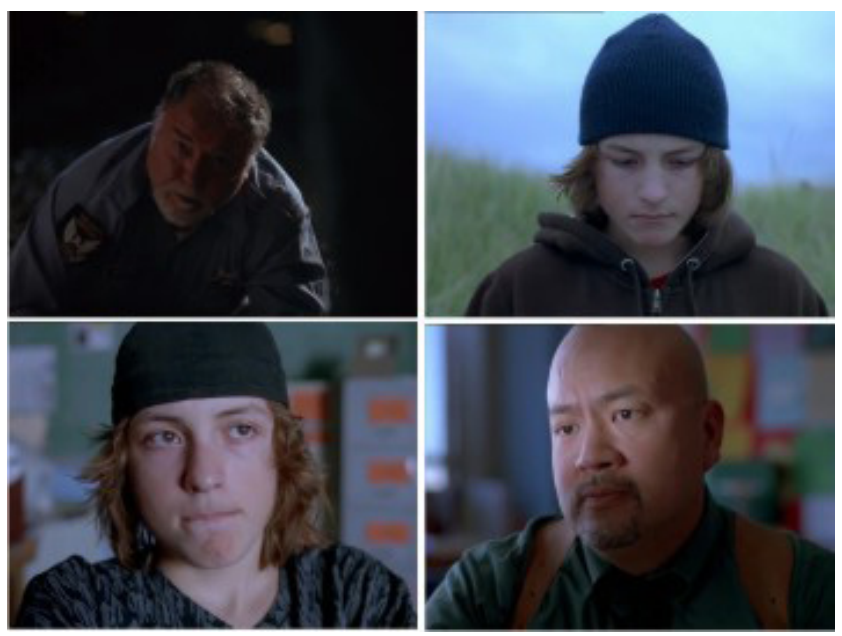

4 planos sucesivos, 4 rostros, 4 espacios-tiempos: de la imagen traumática a su elaboración posible por el encuentro con el Otro.
Por último, las elecciones de la puesta en escena, la construcción de la película, muestran la voluntad de Gus Van Sant de dar cuenta del traumatismo que sufre el personaje y de la elaboración progresiva que lo sigue. Pero Van Sant ofrece otro lugar al espectador: no se trata de ceñirse a la visión de Alex y aún menos de hacerle pasar al espectador lo que el personaje ha pasado. Al contrario, Van Sant hace todo lo posible para preparar la visión del accidente sin por ello ocultar su violencia, ni su crudeza. El cineasta elige entonces afrontar la cuestión de la imagen violenta, potencialmente traumática, y de su impacto sobre el espectador. Esta cuestión atraviesa todo el cine de Van Sant, que resulta ser una forma de respuesta, según dos grandes modalidades, a la manera en que las imágenes pueden constituir una forma de efracción violenta para la mirada.

\section{Luchar contra la imagen como agujero negro}

Gus Van Sant, en algunas entrevistas y por medio de muchas de sus películas, cuestiona el tratamiento mediático de los sucesos policiales y, más ampliamente, de la muerte. To die for, Gerry, Elephant, Last days, Harvey Milk son todas películas que se basan en noticias relacionadas con una muerte violenta. Esto es, por ejemplo, lo que declara Gus Van Sant en $2016^{1}$ con respecto al suceso que inspiró To die for: "Fue una de las primeras veces en que un suceso fue cubierto por tantos periódicos y cadenas de televisión diferentes; en que tantos periodistas se mezclaron en la misma pequeña ciudad para cubrir el mismo pequeño incidente. El asunto había intrigado a tanta gente que parecía un congreso de periodistas. El circo mediático era uno de los temas de la novela, y creo que también es uno de los elementos que me hicieron reaccionar a la muerte de Kurt Cobain y a la matanza de Columbine. Las tres películas, entonces, se relacionan". En la misma entrevista, el cineasta evoca el suceso que da origen a Elephant: "Elephant tiene su origen en la cobertura mediática de la masacre de Columbine. Hubo tantos artículos sobre el tema, tantas emisiones de televisión y documentales... (...) Había investigaciones de todas partes, pero ninguna que haya recurrido a la ficción, porque la ficción era, o lo es aún, considerada como divertimento, sin utilidad para la investigación ni valor psicológico o de la naturaleza que sea. Parece algo de mal gusto hacer una película sobre una tragedia en el momento de los hechos, pero no lo es hacer un documental o una cobertura en un informativo. (...) 
Me parecía que la ficción tenía un papel que desempeñar en todo esto". Estas palabras confirman el hecho de que las películas de Gus Van Sant, al menos algunas de ellas, proceden, en parte, de una reacción de su autor a sucesos mediatizados. También muestran que él se plantea el lugar y el poder del cine de ficción, en comparación con los otros medios, en la representación del hecho. $\mathrm{El}$ inicio de To die for es un buen ejemplo de esto. En él, el espectador descubre, al principio, una jauría de periodistas que persiguen a Susan Stone, acusada en ese momento de haber orquestado la muerte de su marido. Gus Van Sant elige mostrar a los periodistas fascinados por la muerte al punto de ya no pensar: encuadra cuerpos sin cabeza, sus piernas corriendo en la nieve en un cementerio, cámaras que apuntan a Susan Stone, vestida de viuda.

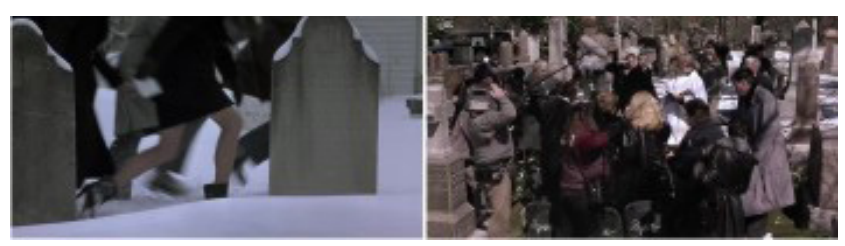

A continuación, vemos imágenes de primeras planas y artículos de periódicos sensacionalistas: la repetición de términos que asocian sexo y muerte, destacada por encuadres cada vez más apretados, parece emanar directamente de esa relación de goce con la muerte que encarnan los medios. Los créditos ponen también en escena la manera en que el tratamiento mediático del suceso desemboca en una disolución del discurso y de las imágenes: Gus Van Sant opera un agrandamiento tal en los textos y fotografías de las revistas que lenguaje e imagen terminan reduciéndose a una sucesión de puntos abstractos.

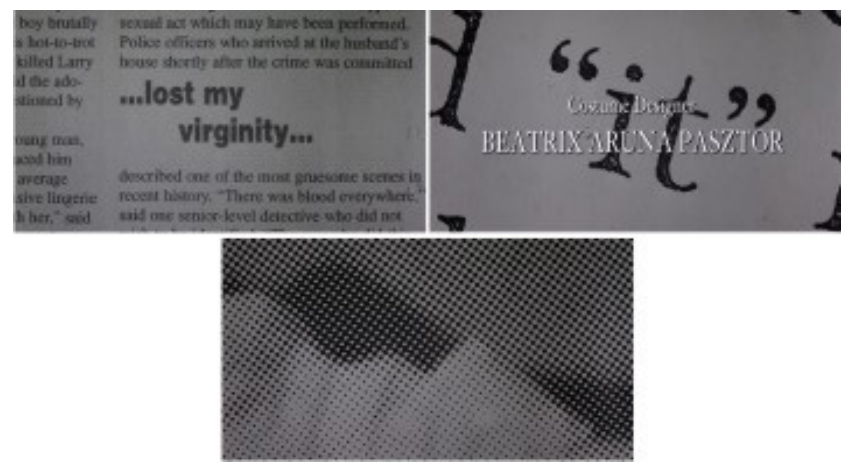

Disolución de la imagen y el discurso: cuando el suceso produce goce y enceguecimiento.

La voz en off de Suzanne, que da inicio a la entrada en el relato, sigue el mismo camino: "La vida entera es un aprendizaje. Todo es parte de un gran plan. Pero a veces es difícil descifrarlo. Cuando uno se acerca demasiado, no ve más que puntitos. Para ver la imagen, hay que tomar distancia. Cuando uno toma distancia, todo se vuelve claro". Sin embargo, el travelling hacia atrás que, en el mismo momento, hace aparecer la mirada de la joven no es de ningún modo una puesta en perspectiva, al contrario: es una zambullida en la imagen. En efecto, descubrimos más tarde en la película que Suzanne está filmándose frente a la cámara, poniéndose en escena en una entrevista-confesión que sueña con vender a una cadena de televisión. La imagen que acompaña el discurso de Suzanne es, entonces, todo menos una puesta en perspectiva: estamos literalmente absorbidos por la pantalla, por medio de un ojo, el de la cámara, que constituye un pozo sin fondo narcisista y mortífero. ${ }^{2}$

A esta zambullida en la imagen que constituye el tratamiento mediático del suceso al que Suzanne adhiere al punto de perderse en él, Gus Van Sant opone otra modalidad, que constituye un auténtico examen detallado y toma de distancia frente a la imagen. Esto es lo que declara el cineasta sobre Elephant en otra entrevista: " $\mathrm{Mi}$ primer recuerdo, es el plano del asesinato de Kennedy: el trayecto del auto, cómo estaba ubicado el cuerpo del presidente, la ubicación del tirador, por dónde pasó la bala. Recuerdo perfectamente todos estos detalles por los planos que habían publicado los periódicos”. ¿Por qué evocar el asesinato de Kennedy? El acontecimiento marcó a Van Sant como a muchos estadounidenses, y como puede marcar a un niño, puesto que tenía 11 años en ese momento. Sin embargo, no evoca las imágenes del acontecimiento en sí, extremadamente chocantes ya que se podía ver el cráneo del presidente explotar con el impacto de la bala, sino de la representación esquemática de los hechos. El uso del mapa, el esquema, como proceso de elaboración y distanciamiento de una imagen mortífera y traumática aparece en muchas películas del cineasta. En Paranoid Park, se difunde en el noticiero que mira Alex el croquis del accidente. En esta secuencia, el discurso del adolescente se reduce a un "Oh, shit!", cuando en realidad está estupefacto por lo que ve al punto de cubrirse la boca y abrir los ojos como platos, lo que se destaca con un primerísimo primer plano de su mirada. La reacción del adolescente es la exacerbación de la angustia que siente todo espectador frente a una imagen televisiva violenta que irrumpe, especialmente en el marco de los breaking news y otros "flashes especiales", términos que además, en sí mismos, hablan de irrupción. Sin embargo, a esta altura de la película, Gus Van Sant ofrece al espectador solo el croquis del acontecimiento, 
dejando fuera de campo lo esencial del reportaje de televisión y alejándose de todo lo que podría dar lugar a una relación problemática con la imagen. Para Elephant, Gus Van Sant concibió un croquis muy preciso que pone en escena las trayectorias de diferentes adolescentes en el interior de un liceo hasta la masacre final. Explica que "la idea era partir de la objetividad de un suceso, es decir, de la ubicación de cada uno durante la matanza, de sus movimientos en función de las actividades del día, para luego mostrar eso con trayectos filmados que se cruzan y vuelven a cruzar". ${ }^{4}$ En la misma película, al igual que en Paranoid Park, las escenas de la clase de ciencias dan lugar a la representación esquemática de fenómenos naturales que evocan, por analogía, acontecimientos violentos que son el corazón de la diégesis. En Elephant, la matanza que azota al liceo puede asociarse al esquema del encuentro de partículas y a la liberación de energía que produce. En Paranoid Park, la caída mortal que provoca Alex se hace eco de una representación del principio de Arquímedes.

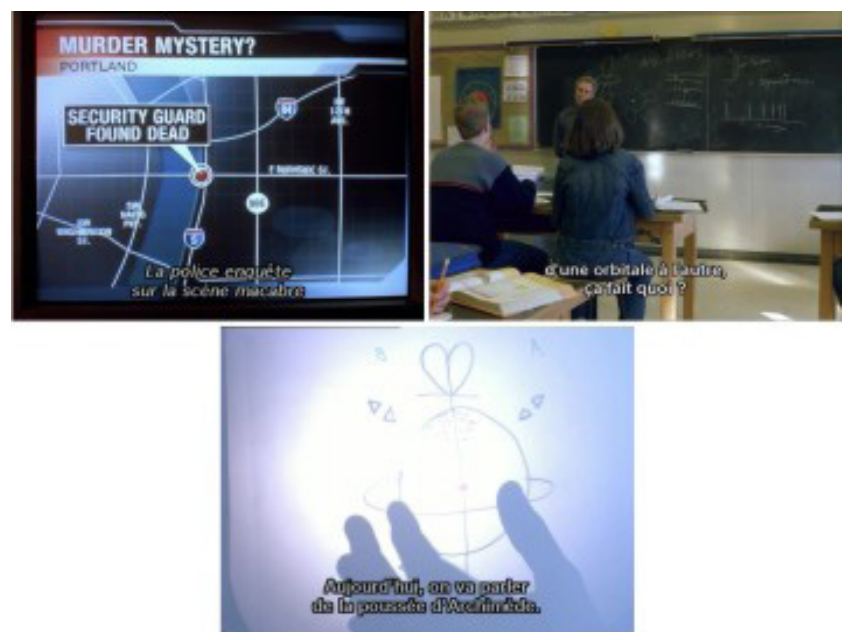

Por último, en Gerry, los dos personajes, perdidos en el desierto, dibujan el borrador de un mapa en la arena, tentativa de encontrar una salida que resulta irrisoria, pero que se basa en el mismo deseo de poner distancia frente al acontecimiento, de abstraerse de él produciendo una abstracción. Los dos Gerry son filmados en contrapicado vertical, como si el objetivo de la cámara fuera el mapa mismo, la superficie plana. Para Gus Van Sant hay, entonces, una manera de emerger, no solo en el relato sino también por el cine: en sus películas, una modalidad de imagen en dos dimensiones, plana, esquemática, se plantea como respuesta a la profundidad de la imagen mediática o cinematográfica en lo que esta tiene de absorbente. Al agujero negro, que no muestra nada, no dice nada, pero que genera susto, sideración y goce com- pulsivo, el cine de Gus Van Sant opone una imagen de dos dimensiones, una modalidad de representación que supone una distancia apta para dar signo y sentido. En su obra también se transparenta una segunda modalidad que cuestiona la práctica del remake.

\section{Del remake al deslizamiento}

Algunos procedimientos de remake o de práctica de citación en el cine podrían interpretarse como la repetición compulsiva de una imagen que produjo efracción. La expresión misma de "remake" invita a pensarlo como tal, puesto que se trata literalmente de "re-hacer" una película. Por ejemplo, el asesinato de Kennedy generó un trauma tal en la nación norteamericana, que la imagen resurgió de manera compulsiva en el cine estadounidense de los años 1970, cine en el que se exacerbó la violencia y en el que se multiplicaron los cuerpos que explotaban con el impacto de las balas. El cine replicó de manera compulsiva también otras imágenes, incluso del cine mismo: las del asesinato de Marion Crane en la ducha de su habitación de hotel en la película Psycho de Hitchcock (1960). Esta secuencia es una de las más citadas de la historia del cine y esto es así, más allá de la lección de montaje que representa, porque constituye un momento cinematográficamente traumático, un "shock de la intrusión de lo Real”, como escribió Slavoj Žižek: "La muerte violenta de Marion constituye una sorpresa total, un shock sin fundamento en la línea narrativa, que interrumpe bruscamente el desarrollo 'normal'; la escena se realiza de un modo muy 'fílmico', su efecto es un producto del montaje: nunca vemos el cuerpo del asesino de Marion en su totalidad, el acto de asesinato se 'desmiembra' en una multitud de primeros planos que se suceden a un ritmo frenético (la mano oscura que se levanta; la hoja del cuchillo cerca del vientre; el grito de la boca abierta...), como si las repetidas embestidas con el cuchillo hubieran contaminado lo real en sí mismo y causado el desgarro de la mirada fílmica continua (o más bien lo contrario: como si la sombra asesina representara, en el interior del espacio diegético, el poder del montaje en sí mismo)". ${ }^{5}$ En otros términos, el agresor, lo que genera efracción, es el montaje, el cine, y la víctima es la mirada.

Ahora bien, Gus Van Sant realizó una remake de $P s y c h o$. En aquellos lugares en que las citas, repeticiones, remakes son en general más alusivas, Van Sant decidió seguir el guion literario y el técnico de manera extremadamente fiel, por eso la crítica suele definir esta pelícu- 
la como una "remake plano por plano". Por otro lado, lejos de responder a un pedido fundado en el objetivo comercial que suelen perseguir las remakes de películas exitosas, sabemos que Gus Van Sant tuvo que pelear por obtener el aval de los estudios para realizarla. En efecto, la película pudo hacerse gracias al éxito popular y crítico de Will Hunting. Se trata, entonces, de un proyecto muy personal. Pero ¿cómo interpretar el deseo de Van Sant de rehacer la película de Hitchcock? Podemos plantear la hipótesis de que, alejándose de la repetición fílmica asociada a la secuencia de la ducha de Psycho, Gus Van Sant se pega al original con el objetivo de neutralizar la potencia cinematográficamente traumática.

En primer lugar, subrayemos el hecho de que, como la película es muy fiel al original, la muerte de Marion Crane pierde su poder de sorpresa y de sideración o susto porque el espectador muy probablemente sabe a qué lo expondrá la película. Por otro lado, Gus Van Sant no es totalmente fiel a la película de 1960 e introduce detalles, elementos, que minan el efecto de la secuencia inicial. Slavoj Žižek, en Jacques Lacan dentro y fuera de Hollywood, criticó esas modificaciones con el pretexto de que debilitan el poder de la escena original. La decepción que expresa Žižek destaca justamente aquello en lo que la versión de Psycho de Gus Van Sant no es una remake. Algunas características de la película original se agrandaron tanto que se vuelven casi grotescas y eso neutraliza su carácter inquietante. Por ejemplo, el agujerito que Norman Bates hizo en la pared de su oficina para jugar al voyeur se vuelve un agujero enorme en la película de Van Sant. Incluso más, Bates se masturba con insistencia en su versión, algo que la puesta en escena destaca ostensiblemente. Por otra parte, mientras la enormidad del agujero, el gesto masturbatorio, hablan de la satisfacción libidinal, el asesinato pierde toda necesidad para el personaje de Bates. Por último, Van Sant introduce en la secuencia de asesinato dos motivos visuales que no están en la obra original: el iris de Marion que se dilata y un plano de nubes volando aceleradamente en el cielo. El inserto sobre el iris de Marion hace de su ojo un agujero negro que subraya la característica absorbente de la imagen y el montaje en la secuencia original, característica que Van Sant comenta con este plano y de la que pretende alejarse. En cuanto a las nubes volando en el cielo, se escapan del sistema hitchcockiano y debilitan, de este modo, la potencia de la ruptura del montaje por su misma heterogeneidad y por la huida que organizan hacia un espacio exterior, un lugar otro, que es también el cine de Gus Van Sant. Así, esos planos de nubes, re- currentes en las películas del cineasta, afirman su lugar y mirada en la versión de Psycho que realiza en 1995. Para profundizar la comprensión de la presencia de esos dos motivos, hay que examinar lo que significa el estatus de la cita de Hitchcock en la obra de Van Sant.

También en ese tema, Paranoid Park ofrece respuestas. De hecho, en esta película las citas hitchcockianas abundan. Los encuadres de Alex vistos desde el exterior de la casa de Jared, donde se refugia la noche del accidente, recuerdan aquellos de La ventana indiscreta (Rear Window, 1954). Para intentar calmar su angustia, Alex toma una ducha. Esta secuencia y los planos que le siguen se presentan como la reescritura del asesinato de Marion Crane en Psycho. Por otra parte, la pared de la cabina de la ducha tiene un motivo de pájaros y en la banda sonora interviene, de manera antinatural, lo que podría parecerse a sonidos de aves. Además de la presencia del pájaro en Psycho (el apellido de Marion significa "grulla", el ave rapaz disecada que destaca en la oficina de Bates), esos pájaros visuales y sonoros pueden evocar la película de terror que realizó Hitchcock en 1963, Los pájaros (The Birds). Por último, la escena del accidente del guardia evoca la caída y muerte del asesino en La sombra de una duda (Shadow of a Doubt, 1942). Sin embargo, ninguno de esos motivos hitchcockianos funciona a modo de cita. Van Sant los desplaza y neutraliza en ellos sistemáticamente la potencia inquietante que, en Hitchcock, se vuelve contra el espectador. En Paranoid Park, la víctima aplastada por el tren no es un asesino como sí es el caso en la película de Hitchcock, lo que justificaba que el espectador pudiera aceptar su muerte sin remordimientos, gozando incluso, tal vez, por su desaparición. A diferencia de lo que sucede en La ventana indiscreta, la instancia que Alex observa es una ficción que atañe a la interioridad del personaje, agitado por su sentimiento de culpabilidad. El relato de Hitchcock, en cambio, pone en escena el enfrentamiento de un voyeurista con un asesino, que finalmente hace del asesino un voyeurista. Ahora bien, Alex no vio nada del accidente, porque fue incapaz de pararse frente al hecho; es a la vez el que mató y el que fue muerto. Es así además que, por deslizamiento, él ocupa en Paranoid Park el lugar que ocupaba la víctima, Marion Crane, en la ducha hitchcockiana. En cuanto a los pájaros, instancia que materializaba en la película de Hitchcock no solo las pulsiones desbordantes del personaje sino también las del espectador, al punto de destruir los cuerpos y de hacer implosionar la imagen, son en adelante una imagen estampada en los azulejos del cuarto de baño y retoman así su lugar cinematográfico, quedándose, por decirlo de algún 
modo, en su lugar de imágenes. De esta manera, en Van Sant, si la integridad psíquica del personaje está amenazada, la amenaza proviene del interior, es decir, de la diégesis y no de la puesta en escena y el montaje, es decir, del cine. Sobre todo, el espectador ocupa un lugar totalmente diferente al del personaje, lugar que le ofrecen justamente la puesta en escena y el montaje: no se encuentra nunca amenazado por una imagen que buscaría sorprenderlo y tomarlo en su sillón, como sí es el caso en Hitchcock.

Retomemos el ejemplo de La sombra de una duda: en la película de Hitchcock, el cuerpo de Charlie, el asesino, cae de un tren a la vía férrea al final de la película. No vemos nada del cadáver, que desaparece en el corte entre dos imágenes. Por otra parte, para la realización de la escena, Hitchcock recurre a la técnica de la pantalla traslúcida, que consiste en filmar una escena frente a otra imagen retroproyectada en dicha pantalla. En su caída, el cuerpo de Charlie no choca contra un tren sino contra la imagen de un tren y es el corte del montaje el que corta su cuerpo. Además, la imagen de la caída de Charlie se funde en otra imagen, la de un vals, por medio de un fundido encadenado. ¿Podríamos afirmar, entonces, que al cuerpo de Charlie no lo aplasta tanto un tren como lo absorbe y destruye la imagen, lo suprime el corte $y$, finalmente, desaparece en el motivo espiralado de un vals cinematográfico? En Paranoid Park, Gus Van Sant coreografía la caída del guardia sobre las vías de una manera bastante parecida a lo que hace Hitchcock, con los brazos y las piernas separados, pero, en cambio, nos muestra el efecto que una caída tal tiene sobre un cuerpo, y eso marca la diferencia. Mientras que Hitchcock hace desaparecer literalmente el objeto del delito en la imagen y el corte, todo sucede como si Gus Van Sant rechazara la potencia del montaje, su capacidad de amenazar la integridad del sujeto, sujeto personaje y también sujeto espectador, así como también de ocultar toda consecuencia ligada a la elección y utilización de las imágenes que se ofrecen a la mirada del espectador. Para el director no se trata, entonces, de negar el corte, sino de inventar una modalidad de corte, por lo tanto de montaje, que permita aprehender la violencia y la muerte sin ocultarla ni repetirla, que permita afrontar la imagen.
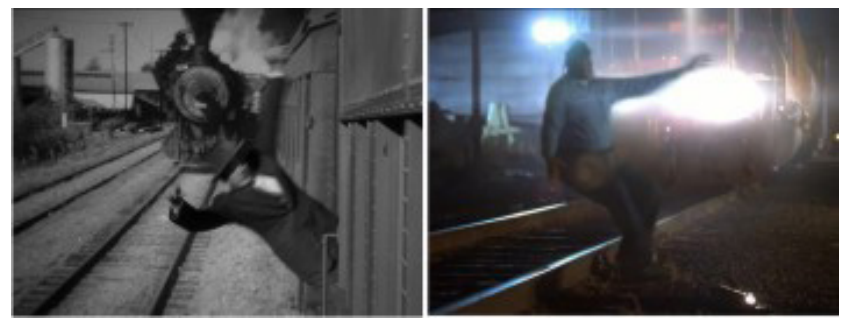

En la última parte de Paranoid Park, descubrimos a Alex acostado en el suelo frente a su casa, literalmente cortado en dos, clavado en el suelo bajo el skate sobre el que debería deslizarse. Su cuerpo en el suelo es un resurgimiento del cuerpo del guardia, cortado en dos sobre la vía férrea. Macy, la amiga de Alex que le sugirió registrar por escrito lo que lo atormenta y de lo que no logra hablar, pasa por la calle en ese momento y le propone que se suba al skate y se deje deslizar enganchándose de la parte de atrás de su bicicleta. Ella restablece así la integridad y la unidad del cuerpo de Alex y le da acceso al movimiento de deslizamiento que, desde el accidente, le está vedado.

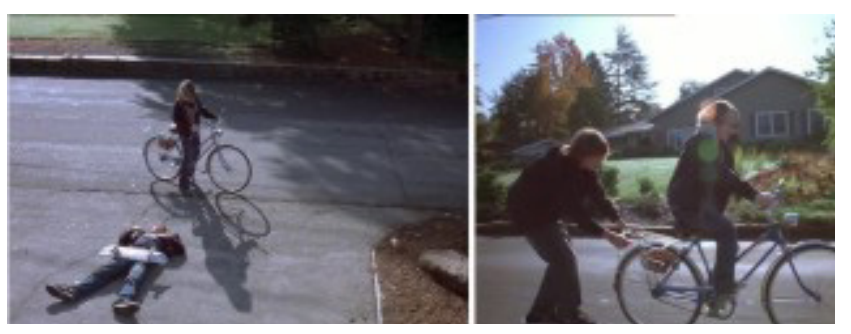

El deslizamiento como respuesta al corte en Paranoid Park.

Del mismo modo, el montaje en Gus Van Sant opone al corte brutal, al cut que corta y desaparece, lo que podría llamarse "montaje por deslizamiento", modalidad que consiste en asociar, al mismo tiempo, ruptura de imágenes y fluidez del movimiento. El montaje en Gus Van Sant no retoma el principio del raccord clásico, que oculta el corte con encadenamientos lógicos o similitudes formales entre planos, dando así la ilusión de su continuidad, ni el de la elipse, que permite ocultar lo que debe quedar invisible. Por ese motivo, el cineasta no hace cortes, entendidos como efectos de montaje. Lo que cuenta es superar el corte, la efracción, para alcanzar una nueva modalidad, que permitiría deslizarse nuevamente de una imagen a otra. La imagen, incluso la más brutal, no debe ocultarse ni exhibirse sin preparación. El corte, por más visible que sea, debe permitir a cada imagen integrarse en el flujo de la película y, por lo tanto, de la representación, por medio de un montaje que permita ver sin ser siderado de él. El montaje en Van Sant tiene la capacidad de oponerse al principio de inercia asociado a la pulsión escópica, a la sideración del sujeto, a su desaparición en una imagen que da vueltas en sí misma, en una repetición sin fin. En el trabajo de Gus Van Sant, lo singular es la voluntad del cineasta de ir más allá de los procedimientos de corte, descomposición, recomposición, que son los fundamentos esenciales del montaje, para ofrecer al espectador una especie de utopía cinematográfica que estaría en el orden del deslizamiento. 
Es posible entonces comprender por qué el cierre de Paranoid Park es una secuencia de skate que mezcla lo documental con la ficción, en la que Alex sale del círculo y del túnel y se integra a la comunidad de skaters, a la que soñaba con pertenecer. Esta secuencia une movimientos diferentes de plano en plano, producidos por skaters diferentes: algunos son jóvenes skaters que Gus Van Sant filmó con una perspectiva documental, otros son personajes de la ficción, como Jared, Alex y sus amigos. Por primera vez, Alex patina con los otros y la comunidad se produce por el montaje. Además, el hecho de patinar no se asocia ni a la confusión y la desconexión de lo real, ni al choque y la preocupación. Esta secuencia final se distingue, en efecto, de las secuencias de skate que se suceden en la película y que la preceden. Por ejemplo, cuando Alex va por primera vez a Paranoid Park con Jared, parece que la imagen ondulara, especialmente por el uso de la cámara lenta. Por un efecto de montaje, el cuerpo de Alex, que observa a los skaters desde el borde del parque, se sustituye con el cuerpo de un adolescente en acción: el adolescente se desdobla, separado de sí mismo y de los otros. Más tarde, una secuencia de tipo documental nos muestra a skaters anónimos, con la mirada oculta por un recorte negro. Van Sant encadena los planos de una manera bastante brutal, sin principio de continuidad. En Paranoid Park existe entonces un tercer principio de construcción: la película está estructurada por una serie de secuencias que ponen en escena skaters según un principio de progresión que conduce al final de la película al deslizamiento bien logrado, el de la comunidad de adolescentes en su skate, operado por el montaje.

\section{Conclusión}

La obra de Gus Van Sant pone en escena personajes perseguidos por un traumatismo y deja aparecer modali- dades de superación de la imagen traumática que se asemejan a otras maneras de "emerger".

Para el personaje, se trata de elaborar una representación que pasa por una puesta en palabras del evento, palabras que permiten la emergencia de una representación, una puesta en imágenes, la película. Esta elaboración convierte al personaje en un cuerpo que se desliza, imagen recurrente en las películas del cineasta, donde el retorno a la vida de los protagonistas pasa por su circulación en bicicleta, sobre patines de hielo o en un barco que se desliza en el agua... El cuerpo se desliza porque realiza una travesía, entendida como crisis pero también como encuentro con un otro que inspira y muestra el camino. El cuerpo adolescente, por el hecho mismo de su puesta en crisis, es la figura seminal de la metamorfosis que opera el cine de Gus Van Sant: deslizamiento de un estado a otro que se traduce en figuras de puesta en escena.

Para el cineasta, dos modalidades de imágenes diferentes intentan responder a una visión traumática producida por la televisión o el cine. La elaboración de representaciones en dos dimensiones, esquemas, mapas, planos, como tantas otras superficies, permite abstraerse del evento, dotarlo de abstracción y, por lo tanto, evitar toda posibilidad de ser atrapado en su profundidad, por la tercera dimensión de un agujero negro que desaparece o enceguece. Los procedimientos de deslizamiento, especialmente por el montaje, permiten superar el corte, salir de la repetición como remake, e integrar el evento a una cadena de imágenes y sonidos dinámica y abierta. Los planos de nubes atravesando el cielo, que son tan frecuentes en la obra del cineasta, podrían constituir el motivo del deslizamiento por excelencia, imágenes fundadoras del cine a la manera en que Van Sant pretende practicarlo.

“¿Hacia dónde van las nubes en tus películas?”

"No lo sé. Son dibujos que se arman y desarman en el cielo. No tienen un objetivo preciso. Para mí son, simplemente, la expresión más pura del cine."

\section{Traducción: Salomé Landivar}

\footnotetext{
1 Orléan, M. (coord.) (2016), Gus Van Sant : icônes, París, Cinémathèque-Actes Sud, p. 148.
}

2 Esta entrevista, que Suzanne sueña con vender a la televisión, es la que, además, hará que ceda a las propuestas de un asesino a sueldo que ella toma por un periodista y que la conducirá a la muerte.

3 Baecque, A. de (22 de octubre de 2003). "Un éléphant très dessiné [Un elefante muy dibujado]", París. Libération.

4 Ibid.

5 Žižek, S. (2010), Tout ce que vous avez toujours voulu savoir sur Lacan sans oser le demander à Hitchcock, "en sus ojos insolentes, veo mi pérdida escrita”, París, Capricci, p. 279 [trad. esp.: (1994), Todo lo que usted siempre quiso saber de Lacan y nunca se animó a preguntarle a Hitchcock, Buenos Aires, Manantial].

6 Baecque, A. de (22 de octubre de 2003), “Un 'éléphant' très dessiné”. Libération. 